\title{
Decreased Cerebellar 3',5'-Cyclic Guanosine Monophosphate Levels and Insensitivity to Harmaline in the Genetically Dystonic Rat (dt) ${ }^{1}$
}

\author{
JOAN F. LORDEN, ${ }^{*}, 2$ GARY A. OLTMANS,§ TINA W. MCKEON, $¥$ JACQUELINE LUTES, ${ }^{*}$ AND \\ MITCHELL BEALES§
}

Departments of * Psychology and $\ddagger$ Anatomy, University of Alabama in Birmingham, Birmingham, Alabama 35294 and $\$$ Department of Pharmacology, Chicago Medical School, North Chicago, Illinois 60064

\begin{abstract}
The dystonic rat (dt) is an autosomal recessive mutant displaying a complex motor syndrome that includes sustained axial twisting movements. The syndrome is correlated with increased glutamic acid decarboxylase activity in the deep cerebellar nuclei and increased cerebellar norepinephrine levels in comparison with phenotypically normal littermates. Biochemical, behavioral, and anatomical techniques were used to investigate the possibility that the abnormalities noted in the cerebelium of the $d t$ rat were indicative of altered function of the major projection neurons of the cerebellar cortex, the Purkinje cells. Phenotypically normal rats showed tremor in response to harmaline, a drug that acts on the inferior olive to produce bursting in the climbing fiber pathway. Dystonic rats were insensitive to the effects of harmaline but did respond to oxotremorine. Levels of the cyclic nucleotide $3^{\prime}, 5^{\prime}$-cyclic guanosine monophosphate, a biochemical marker for Purkinje cells, increased in response to harmaline in normal rats but were significantly lower in dystonic rats under both basal and harmaline-stimulated conditions. Purkinje cell soma size was reduced in the dystonic rats but no other morphological correlates of the behavioral or biochemical deficits were noted. Taken together with other observations on this mutant, the results suggest an impairment in the cerebellum or in its connections with lower brainstem and spinal cord sites.
\end{abstract}

The dystonic $(d t)$ rat displays sustained twisting movements of the axial musculature during waking (Lorden et al., 1984). Hyperflexion of the trunk, frequent falls to the side with rigid extension of the limbs, and poor limb placement during locomotion are also characteristic of the disorder. The rat disease is inheriled as an autosomal recessive mutation and the clinical syndrome is observed beginning on postnatal days 9 to 10 , following a period of apparently normal motor development. The mutant has been proposed as a model for dystonia musculorum deformans (DMD), an inherited neurological disease of unknown pathogenesis. As in the human disease, the syndrome in the mutant rat is not associated with any morphological

Received October 5, 1984; Revised March 18, 1985;

Accepted April 10, 1985

\footnotetext{
1 This work was supported by Grant NS18062 from the National Institute of Neurological and Communicative Disorders and Stroke. We would like to thank Dr. Paula Hoffman for the use of her microwave oven and Jeanette Milligan for her care of the breeding colony.

${ }^{2}$ To whom correspondence should be addressed.
}

abnormality in the central or peripheral nervous systems (Eldridge, 1970; Zeman, 1970; Lorden et al., 1984).

Investigations in motor and non-motor areas of the central nervous system of the dt rat have yielded evidence of biochemical disturbances in the cerebellum. Animals displaying the motor syndrome have increased glutamic acid decarboxylase (GAD) activity in the deep cerebeliar nuclei (Oltmans et al., 1984) and elevated levels of norepinephrine (NE) in the whole cerebellum (Lorden et al., 1984). Although it is not known whether these changes are unique to the cerebellum, they have not been detected in any of the other brain regions studied to date. Specifically, GAD activity appears normal in the caudate-putamen, and NE levels are not reliably different from littermate control values in the neocortex and hippocampus.

The cause of the biochemical changes found in the cerebellum of the $d t$ rat is not known. Nevertheless, studies of the effects of lesions on GAD activity in other brain areas provide a framework for developing hypotheses concerning the origin of the abnormalities in the $d t$ rat. For example, in the red nucleus increases in GAD activity have been found following destruction of afferent pathways (NieoulIon and Dusticier, 1981). Since cerebellar GAD immunoreactivity has been localized in the Purkinje cell terminals in the deep cerebellar nuclei (Chan-Palay, 1982), the increased GAD activity of the dystonic rat may indicate a functional deafferentation of the Purkinje cells. Dccreased afferent stimulation could result from a reduction in either climbing fiber or mossy fiber activity (Eccles et al., 1966a, b).

To examine the status of the Purkinje cells and their response to the activation of afferent neurons directly, we have measured $3^{\prime}, 5^{\prime}$ cyclic guanosine monophosphate (cGMP) levels in the cerebella of dystonic rats and their normal littermates. This nucleotide is thought to be a relatively specific marker for Purkinje cells (Biggio et al., 1977a, b, 1978; Nairn and Greengard, 1983), as cerebellar guanylate cyclase and cGMP have both been localized immunohistochemically in Purkinje cells (Ariano et al., 1982). Furthermore, quantities of cGMP and cGMP-dependent protein kinase, a biochemical marker found solely in Purkinje cells (DeCamilli et al., 1984), are markedly reduced in mutant mice lacking Purkinje cells (Mao et al., 1975b; Schlichter et al., 1980). The finding that cerebellar levels of cGMP are increased when excitatory input to the Purkinje cells is enhanced indicates that cGMP reflects Purkinje cell activity (Biggio et al., 1977a, b).

Measurements of cGMP were made in $d t$ rats both under unstimulated conditions, to examine basal levels of cyclic nucleotide, and following treatment with harmaline, to assess the effects of afferent activation. In normal animals harmaline produces a generalized motor tremor and an increase in cerebellar cGMP levels (Lamarre et al., 1971; Mao et al., 1975a). Electrophysiological recording from Purkinje cells shows that the frequency of simple spikes decreases and 
a bursting pattern of complex spikes is elicited (Lamarre et al., 1971). These effects are thought to be caused by harmaline's induction of a synchronous firing pattern in the cells of the inferior olive which in turn drives the Purkinje cells by way of the climbing fiber pathway (Lamarre and Mercier, 1971; Lamarre et al., 1971; Biscos et al., 1973; De Montigny and Lamarre, 1973; Llinas and Volkind, 1973; Lamarre and Puil, 1974; Guidotti et al., 1975). The Purkinje cells in turn drive a cerebellobulbar pathway that co-activates $\alpha$ - and $\gamma$ motoneurons to produce tremor (Lamarre and Weiss, 1973).

In addition to measuring the effects of harmaline on cerebellar cGMP levels, we measured the effects of harmaline on gross locomotor activity and monitored both $d t$ rats and their normal littermates for the appearance of tremor following treatment with harmaline or oxotremorine. The tremorogenic actions of oxotremorine are believed to be mediated by systems other than the climbing fibers (Guidotti et al., 1975). In addition to the biochemical and behavioral measurcments, the Purkinje cells and the projection from the inferior olivary complex were examined using anatomical techniques.

\section{Materials and Methods}

Animals. Dystonic rats and their phenotypically normal littermates were obtained from the colony at the University of Alabama in Birmingham at 16 to 20 days of age. Both males and females were used. Mutants were obtained by mating heterozygotes. Litters were routinely culled to 8 to 10 pups on postnatal day 12 .

Biochemical measures. For measurement of cGMP, eight normal and six dystonic rats 16 days of age were injected with harmaline $(15 \mathrm{mg} / \mathrm{kg})$. An additional seven normal and six dystonic animals were injected with an equivalent volume of physiological saline. Fifteen minutes after injection, the rats were killed by exposure to $2.5 \mathrm{sec}$ of focused microwave irradiation in a Litton microwave oven modified by General Medical Corp. (Peabody, MA). Following irradiation, the brains were removed and the cerebella were dissected and frozen on dry ice. For assay of cGMP, each cerebellum, weighing approximately $130 \mathrm{mg}$, was homogenized with a Brinkman Polytron in $10 \mathrm{ml}$ of ice cold $0.05 \mathrm{M}$ Tris buffer, $\mathrm{pH} 7.5$, containing $4 \mathrm{~mm}$ EDTA. A $250-\mu$ aliquot of the homogenate was added to a glass culture tube containing $250 \mu \mathrm{l}$ of the Tris buffer and was immediately boiled for $3 \mathrm{~min}$. The assay tubes were then centrifuged and duplicale 100- $\mu$ l samples were assayed for CGMP using a commercially available radioimmunoassay kit (Amersham Corp., Arlington Heights, IL). The sensitivity of the assay was better than 0.04 pmol. Protein determinations were made using the Lowry method (Lowry et al., 1951). The data were analyzed with a two-way (drug $x$ phenotype) analysis of variance (ANOVA).

Behavioral observations. Groups of five normal and seven dystonic rats 17 to 18 days of age were used to obtain polygraph recordings of the tremor produced by harmaline treatment. An additional three normal and three dystonic rats were used to test whether the dystonic rats were able to respond to oxotremorine $(0.75 \mathrm{mg} / \mathrm{kg})$. Recordings were made with a Grass force displacement transducer and a Grass model 5 polygraph. The rats were placed in an $8 \times 8 \times 5 \mathrm{~cm}$ Plexiglas box open at the top, but they were otherwise unrestrained. A length of 3-0 silk suture was tied loosely around one hind leg and threaded over the hook of the force transducer. The recordings were evaluated for the appearance of rhythmic activity with a frequency of 10 to $14 \mathrm{~Hz}$ and a duration of at least $0.5 \mathrm{sec}$.

Levels of cerebellar cGMP can increase with increased locomotor activity, although the two effects are pharmacologically dissociable (Breese et al., 1979). To determine whether differences in activity might contribute to any observed differences in CGMP levels between normal and dystonic rats, movements were quantified before and after treatment with harmaline or physiological saline. Normal and dystonic rats ( $n=4 /$ group) were placed in automatic activity-monitoring chambers (Lorden et al., 1984) and injected with either saline or harmaline $(15 \mathrm{mg} / \mathrm{kg}$ ) after a 30 -min preinjection habituation period. The animals were then monitored for an additional $45 \mathrm{~min}$. Average photocell beam crossings for 5 -min periods were obtained for both pre- and postinjection periods. Each animal received both saline and harmaline on successive days. The order of presentation was counterbalanced within each group. Postinjection activity data were analyzed with a $2 \times 2$ (drug $x$ phenotype) ANOVA. Preinjection activity scores of normal and $d t$ rats were compared with a $t$ test.

Anatomical studies. Purkinje cell size and the thickness of the molecular and granular layers in the cerebellar cortex were measured in five normal and five $d t$ rats at 20 days of age. The animals were anesthetized with sodium pentobarbital and perfused intracardially with $0.9 \%$ sodium chloride followed by $10 \%$ neutral buffered formalin. Brains were removed and postfixed in buffered formalin. Before sectioning, the tissue was placed in $30 \%$ sucrose in buffered formalin and allowed to sink. The brains were then serially sectioned in the sagittal plane ( $30 \mu \mathrm{m}$ thickness) on a freezing microtome and stained with cresyl violet.

Cerebellar sections from $d t$ and normal rats were qualitatively evaluated for differences in foliation and cell arrangement. For both cell size and layer thickness measurements, midvermian and paravermian sections were used. The continuity of the superior cerebellar peduncle with the cerebellar medulla served as a landmark for paravermian sections. A total of 24 Purkinje cells in cerebellar folia $V$ and $V I$ from each animal were traced using a Leitz microscope with camera lucida attachment. An equal number of cells meeting the nucleolar criterion were traced from all animals. As a control for the specificity of any effects seen in the cerebellum, 20 pyramidal cells in area CA4 of the hippocampus were also traccd in cach animal.

Layer thickness was assessed by tracing the depths of the molecular and granular layers from the crowns of cerebellar folia $\mathrm{V}$ and $\mathrm{VI}$ in six different sections from each animal. For each sel of measurements, a scale bar was traced for calibration purposes. Measurements were made using a Houston Instruments digitizing pad interfaced to an Apple II Plus computer. R \& M Biometrics (Nashville, TN) software was used to calculate areas and lengths. Statistical comparisons were made between normal and dystonic rats with $t$ tests. Each region was analyzed separately.

To examine Purkinje cell dendritic morphology, $11 d t$ and 12 normal 20day-old animals were anesthetized with ketamine and ether. A 0.5- $\mu$ l Hamilton syringe was used to inject $0.03 \mu \mathrm{l}$ of a concentrated solution of horseradish peroxidase (HRP; $30 \%$ in saline) over a $10-\mathrm{min}$ period. With the aid of a stereotaxic instrument, the injection was aimed at the paravermian cerebellar modulla. The cannula was left in place for an additional 5 min after injection. After 18 to $24 \mathrm{hr}$, the animals were anesthetized with sodium pentobarbital and perfused intracardially with $0.9 \%$ sodium chloride followed by $2 \%$ paraformaldehyde and $2 \%$ glutaraldehyde in $0.1 \mathrm{~m}$ phosphate buffer $(\mathrm{pH}$ 7.2). The brains were removed, placed in $30 \%$ sucrose in $0.1 \mathrm{M}$ phosphate buffer ( $\mathrm{pH} 7.2)$ overnight, and serially sectioned in the sagittal plane $(125 \mu \mathrm{m}$ thickness) on a treezing microtome. The sections were then immersed in a $0.05 \mathrm{M}$ Tris buffer $(\mathrm{pH} 7.3)$. Labeling of transported HRP was performed on the free-floating sections using a modification of the diaminobenzidene (DAB) reaction reported by Robson (1981). This reaction involves incubation of the sections in DAB with $1 \%$ hydrogen peroxide in a $0.1 \mathrm{M}$ phosphate buffer $(\mathrm{pH}$ 7.2) following preincubation in $0.5 \%$ cobalt chloride in $0.05 \mathrm{M}$ Tris buffer $(\mathrm{pH}$ 7.3). Labeled Purkinje cells from $d t$ and normal animals were compared in photographs or camera lucida drawings of the cells. In order to avoid variation due to regional differences in cerebellar development or variation due to differences in the size of animals, comparisons were made between cells from the same regions and from animals matched by body weight.

\section{Results}

Effects of harmaline on behavior and CGMP. All harmaline-injected normal rats used for the cGMP assays developed an obvious tremor prior to sacrifice. No tremor was detected visually in the dystonic group. The cGMP assays (Table I) indicate that after saline injections the dystonic rats had CGMP levels over $60 \%$ lower than those of phenotypically normal littermate controls. Following harmaline treatment, both normal and dystonic rats showed a large increase in cGMP levels. The increase in normal rats was similar to that obtained by other investigators (Mao et al., 1974). Although the dystonic rats did show an increase in CGMP levels, their levels were significantly lower than those of harmaline-treated normal rats and, in fact, did

TABLE ।

Effects of harmaline hydrochloride on CGMP levels in the cerebellum of normal and dystonic rats ${ }^{a}$

\begin{tabular}{llccc}
\hline \multirow{2}{*}{ Group } & \multicolumn{4}{c}{ Treatment } \\
\cline { 2 - 5 } & $n$ & Saline & $n$ & Harmaline \\
\hline Dystonic & 6 & $4.31 \pm 1.40^{b}$ & 6 & $19.19 \pm 9.67^{b . c}$ \\
Normal & 7 & $13.11 \pm 3.44$ & 8 & $34.49 \pm 8.35^{\circ}$ \\
\hline
\end{tabular}

${ }^{a}$ cGMP levels are in picomoles per milligram of protein. Values are means \pm SD. Data were analyzed by a $2 \times 2$ (phenotype $\times$ drug) ANOVA.

${ }^{D}$ Differs from normal rats given the same treatment, $p \leq 0.01$.

${ }^{c}$ Differs from rats of the same phenotype, $p \leq 0.01$. 
not differ from saline-treated normal controls. Protein values for samples used in the assay did not differ significantly among the four groups.

A more detailed analysis of the harmaline-induced tremor was made in a separate group of normal and dystonic animals. Polygraph recordings made prior to and for 30 to $45 \mathrm{~min}$ following harmaline injections in separate groups of animals confirmed the results of visual observations made of animals prior to sacrifice for the biochemical assays. As shown in Figure 1, injection of harmaline in normal rats produced a characteristic $10-$ to $14-\mathrm{Hz}$ tremor with a mean time of onset of 4.0 min (SD 0.7). In normal animals at the dose used, tremor was virtually uninterrupted for the entire period of observation. Dystonic rats were active during the observation period but no evidence of tremor was detected visually or in the polygraph

\section{NORMAL}

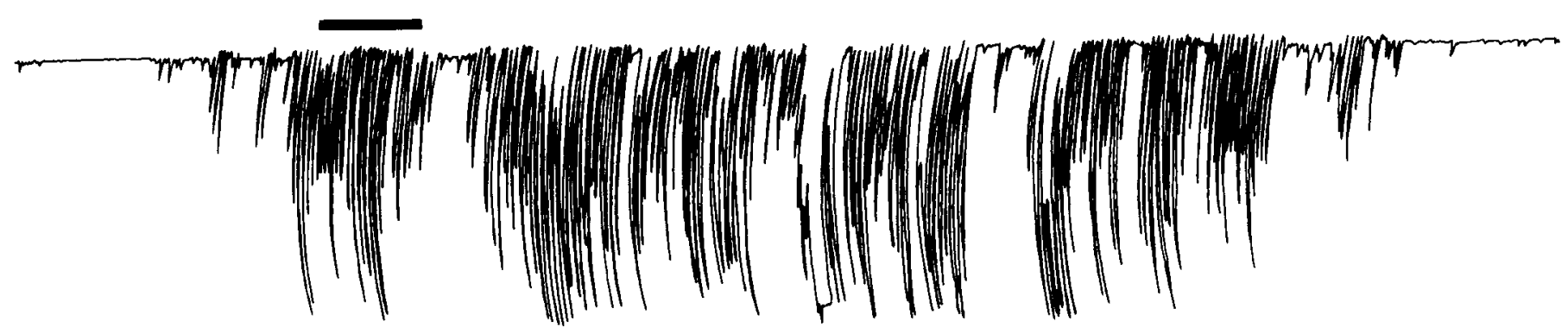

DYSTONIC

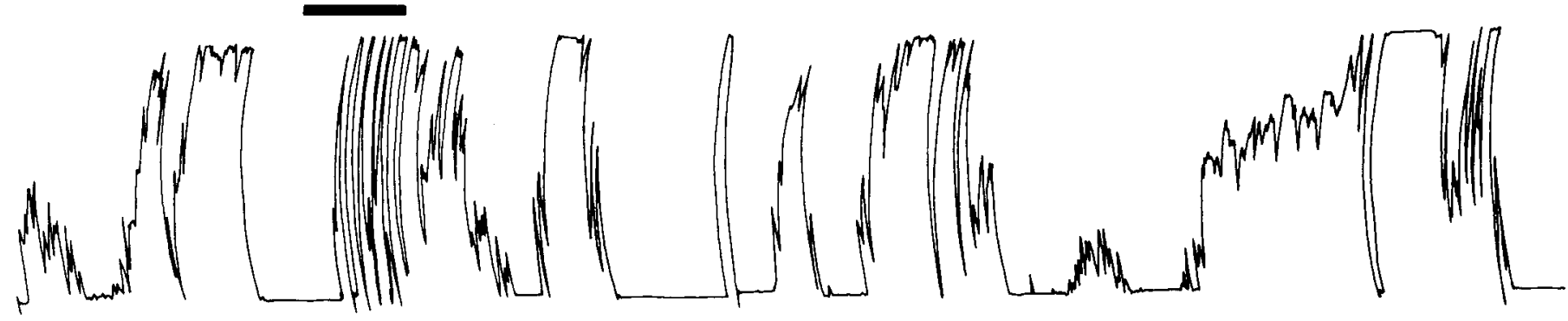

NORMAL

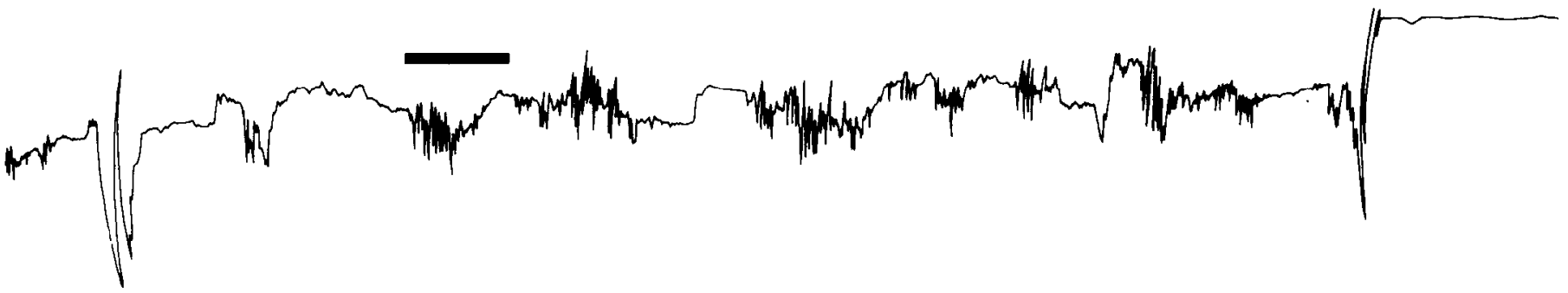

DYSTONIC

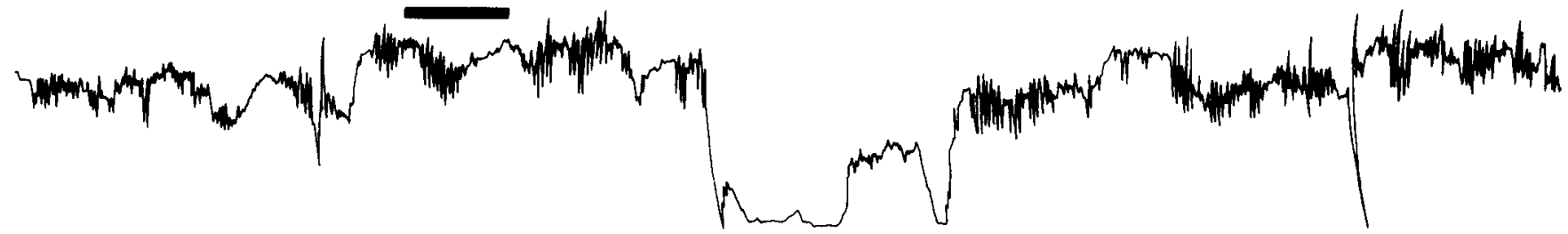

Figure 1. Polygraph recording of characteristic harmaline $(15 \mathrm{mg} / \mathrm{kg}$ ) tremor in a normal 17 -day-old rat (top tracings). Each line is 30 sec long. Locomotor activity in a dystonic rat of the same age was recorded after harmaline injection. No rhythmic activity at a frequency of 10 to $14 \mathrm{~Hz}$ could be detected. Lower frequency activity was associated with sniffing. Oxotremorine $(0.75 \mathrm{mg} / \mathrm{kg})$ produced a characteristic tremor in both normal and dystonic rats at 17 days of age (bottom tracings). Scale bars $=2 \mathrm{sec}$. 
recordings. The records revealed only gross locomotor activity and expioratory behaviors such as sniffing that were readily discriminated by their short duration and lower frequency.

To determine whether the dystonic rats were refractory to other centrally acting tremorogenic agents, oxotremorine was administered to $d t$ and normal rats. The lower panel of Figure 1 shows that oxotremorine $(0.75 \mathrm{mg} / \mathrm{kg})$ caused similar tremor in both normal and dystonic rats. The mean time of onset of the tremor did not differ statistically between normal $(7.7 \mathrm{~min}, \mathrm{SD}=5.5)$ and $d t(8.3 \mathrm{~min}, \mathrm{SD}$ $=2.1$ ) rats.

When the activity of normal and dystonic rats was quantified in photocell chambers, there were no significant differences in activity levels during the habituation period that preceded the injections (Table II). After the 30-min acclimation period in the activity chambers, the animals were relatively inactive. Activity levels were significantly higher after harmaline than after saline injections in both normal and mutant pups. The normal and dystonic groups did not differ from each other after saline injections, but significantly higher levels of activity were evident in the dystonic group after harmaline treatment. This suggests that the lower cGMP levels found in the dystonic animals under either non-drug or harmaline conditions are not a consequence of hypoactivity in the mutants.

Anatomical studies. Purkinje cell size measured in midvermian and paravermian sections was 5 to $11 \%$ smaller in $d t$ than in normal rats (Table III). This was not a generalized effect. The size of hippocampal CA4 pyramidal cells measured as an index of nonspecific change did not differ between the two groups. Mean area $( \pm$ SEM) for $d t$ rats was $295.52 \pm 6.21 \mu \mathrm{m}^{2}$ and for normal rats, 295.70 $\pm 11.05 \mu \mathrm{m}^{2}$. In addition, there were no significant differences between normal and dystonic rats in the thickness of the molecular and internal granular layers. The mean thickness (micrometers) of the molecular layer ( \pm SEM) was $121.67 \pm 8.00$ in $d t$ rats and 121.94 \pm 6.37 in normal animals. In the internal granular cell layer, mean thickness was $306.61 \pm 17.06$ in dystonic rats and $317.38 \pm 15.91$ in normal rats.

Five $d t$ and four normal rats were successfully injected with HRP to produce dense filling of Purkinje dendritic trees. Of these, there were two pairs of normal and $d t$ rats with similar body weights and labeled cells in the same cerebellar regions. It was noted that Purkinje

TABLE ॥

Elfects of harmaline $(15 \mathrm{mg} / \mathrm{kg}$ ) on locomotor activity in dystonic and normal rats

\begin{tabular}{lrc}
\hline \multirow{2}{*}{ Treatment } & \multicolumn{2}{c}{ Mean Activity $( \pm \mathrm{SD})$} \\
\cline { 3 - 3 } & \multicolumn{1}{c}{ Normal } & \multicolumn{1}{c}{ Dystonic } \\
\hline Preinjection & $113.2 \pm 65.3$ & $152.8 \pm 52.4$ \\
Harmaline & $87.0 \pm 20.0$ & $182.6 \pm 55.3^{a}$ \\
Saline & $12.4 \pm 8.9^{b}$ & $61.1 \pm 65.4^{b}$ \\
\hline
\end{tabular}

${ }^{a}$ Differs from normal animals given the same treatment, $p \leq 0.05$.

${ }^{b}$ Differs from harmaline trial, $p \leq 0.05$.

TABLE III

Planimetric measurements of Purkinje cell area in the cerebella of 20-dayold dystonic and normal rats

Camera lucida drawings of six cells from each of two folia in the vermian and paravermian regions were traced in each rat ( $n=5 /$ group). Values are mean square micrometers \pm SEM for 30 cells.

\begin{tabular}{lll}
\hline \multirow{2}{*}{ Region } & \multicolumn{2}{c}{ Cell Size $\left(\mu \mathrm{m}^{2}\right)$} \\
\cline { 3 - 3 } & \multicolumn{1}{c}{ Normal } & \multicolumn{1}{c}{ Dystonic } \\
\hline Vermis: Folium $V$ & $452.91 \pm 59.58$ & $416.12 \pm 53.89^{a}$ \\
Vermis: Folium $\mathrm{VI}$ & $461.95 \pm 64.4$ & $419.65 \pm 45.55^{a}$ \\
Paravermis: Folium $\mathrm{V}$ & $474.02 \pm 66.05$ & $420.98 \pm 75.7^{a}$ \\
Paravermis: Folium VI & $463.85 \pm 50.47$ & $440.67 \pm 53.37^{a}$ \\
\hline
\end{tabular}

${ }^{a}$ Differs from normal group, $\rho \leq 0.05$, Student's $t$ test. cells in certain folia (e.g., folium I) had less elaborate dendritic arborizations than cells in other folia, and that animals with lower body weights appeared to have less well developed dendritic trees. When these variables were controlled, however, dendritic branching and dendritic spines of labeled Purkinje cells appeared qualitatively similar in normal and dystonic rats (Fig. 2). Photomicrographs of sections of primary dendrites from normal and dystonic rats are shown in Figure 3 . There was no indication that the $d t$ mutation was associated with an increase in dendritic spines, as reported following experimental destruction of the inferior olive (Sotelo et al., 1975; Sotelo and Asenio-Nunes, 1976).

Examination of the medulla in all injected animals showed that HRP was transported from injection sites in the cerebellar cortex to the inferior olive in 20-day-old dt rats as well as normal rats, indicating the presence of the climbing fiber pathway (Fig. 4).

\section{Discussion}

Harmaline tremor. At doses that produced prolonged tremor in normal rats, no evidence of tremor was apparent in the $d t$ rats. This is not the result of an inability to display tremor on the part of the dystonic rat. Both dystonic rats and normal rats responded to the drug oxotremorine. In normal rats harmaline tremor can be blocked by destruction of the inferior olive with 3-acetylpyridine (3-AP) (Simantov et al., 1976). However, loss of the cells of the inferior olive does not explain the lack of response of the $d t$ rat to harmaline, as microscopic study of the brainstem of the dystonic rat in Nisslstained material revealed apparently normal olivary neurons (Lorden et al., 1984). Furthermore, the finding that HRP was transported from the cerebellum to the olive suggests that the olivary cells send a projection to the cerebellum, although the possibility that the projection is reduced in size or topographically disordered cannot be excluded at present. Examination of the dendritic arborization of Purkinje cells in the dystonic rat, however, supports the argument that the projection from the olive to the cerebellum is intact. The Purkinje cells of the $d t$ rat do not exhibit the increase in dendritic spines that follows destruction of the inferior olive (Sotelo et al.,
Dystonic
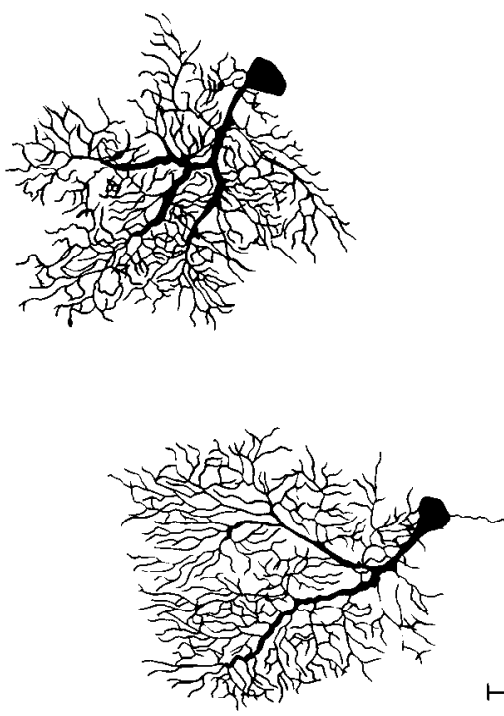

\section{Normal}

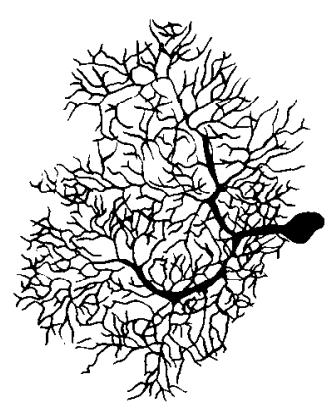

Figure 2. Camera lucida drawings of Purkinje cells in $d t$ and normal rats (body weight $=36$ to $38 \mathrm{gm}$ ). Purkinje cells in folia V and VI in 20-day-otd rats were densely filled following HRP injections into the region of the deep nuclei. Dendritic arborization was qualitatively similar in the two groups when assessed in terms of size and complexity, the orientation of branches, and the appearance of dendritic spines. 

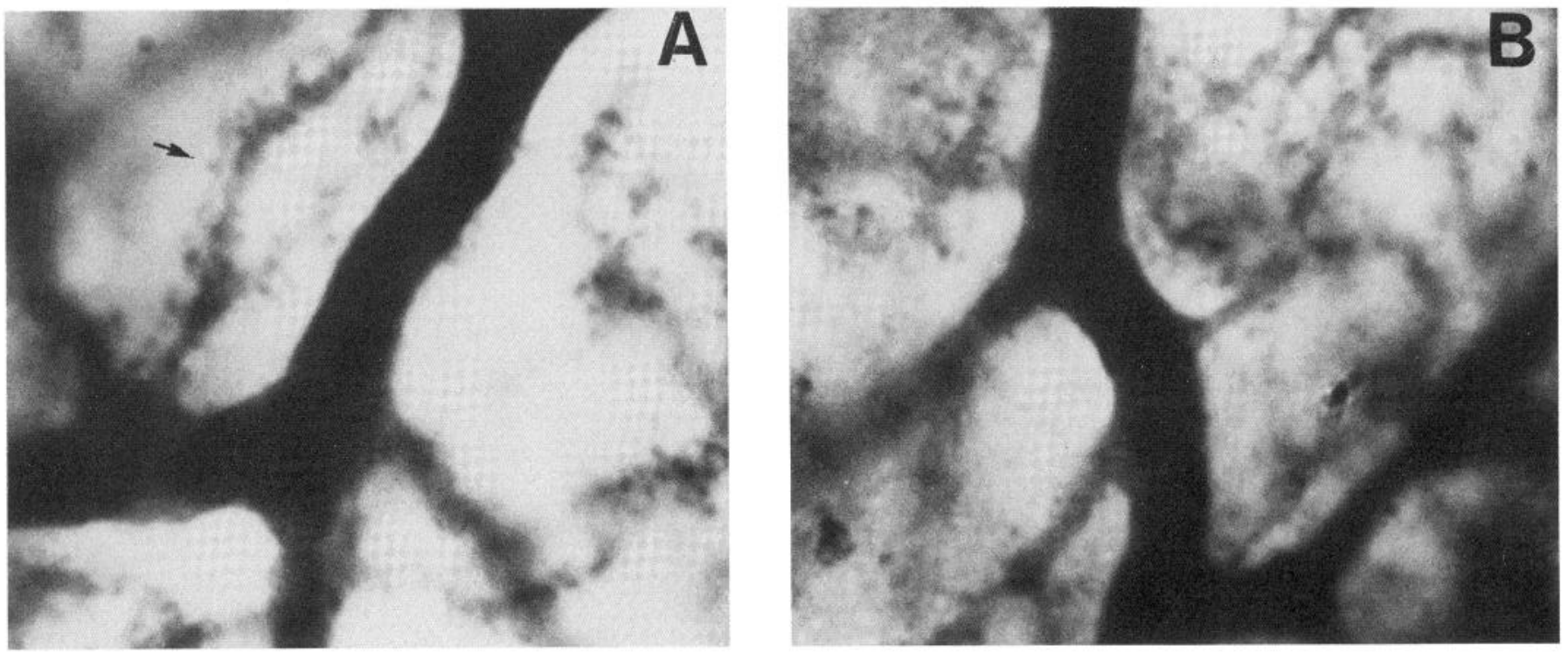

Figure 3. The primary and secondary dendrites from Purkinje cells of dystonic $(A)$ and normal $(B)$ rats show the absence of spines. The presence of spines on other dendrites is indicated at the arrow in $A$.

1975; Sotelo and Arsenio-Nunes, 1976). Finally, the fact that harmaline treatment produced a significant increase in cGMP levels in the dystonic rat must mean that the climbing fiber projection is not only present but at least partially functional. In rats with 3-AP lesions of the climbing fiber system, harmaline-induced increases in cGMP can be completely blocked (Guidotti et al., 1975).

Although the harmaline dose used in the present study $(15 \mathrm{mg} /$ $\mathrm{kg}$ ) exceeds the dose required to produce tremor in normal animals, consideration of the biochemical data raises the possibility that the lack of a tremorogenic effect in the $d t$ rats may have been due to an insufficient dose. Harmaline treatment increased the cGMP levels in $d t$ rats to a level not significantly different from saline-treated normal rats, but significantly lower than harmaline-treated normals. If the elicitation of tremor requires Purkinje cell stimulation sufficient to produce a threshold level of cGMP production, then the absence of a tremor in $d t$ rats may reflect a failure to reach this threshold.

Reduced cGMP. The cause of reduced basal and harmalinestimulated cGMP levels in the $d t$ rat is unknown. However, these effects are not simply a consequence of decreased activity in the mutants. Measurement of activity levels showed that under all conditions, the mutants were as active as, or more active than, their phenotypically normal littermates.

Base line cGMP levels were reduced over $65 \%$ in $d t$ rats. Nevertheless, harmaline treatment produced a significant increase in cGMP in the mutants. If expressed as a percentage of the base line level, the increase in the $d t$ rats (445\%) exceeded that in normal rats $(263 \%)$. Low base line levels of cGMP in the mutants may reflect normal cGMP levels in fewer functional Purkinje cells or fewer functional climbing fiber-Purkinje cell synapses. If so, the potentiated percentage increase following harmaline may indicate a hypersensitive response in the functional Purkinje cells or a recruitment of previously inactive Purkinje cells. When assessed as an absolute change from base line, however, there was no significant difference in the cGMP increase between the two groups. The mean increase of $14.9 \mathrm{pmol}$ of cGMP/mg of protein found in the dystonic rats was not significantly different from the increase of $21.3 \mathrm{pmol} / \mathrm{mg}$ of protein found in the normal rats. This may mean that under non- stimulated conditions, there is a reduced climbing fiber input to the Purkinje cells or, alternatively, that another component of the cerebellar circuitry is having an abnormal damping effect on Purkinje cell activity,

Cerebellar dysfunction in the dystonic rat. The failure of harmaline to produce tremor in dystonic rats suggests the presence of a defect in a specific neuronal pathway that includes the cerebellum. This pharmacological effect does not allow us to specify precisely the locus of the defect. However, the finding of reduced cerebellar cGMP adds to accumulating evidence of cerebellar dysfunction in this mutant. The low levels of cGMP in the cerebellum, increased GAD activity in the deep nuclei, and decreased Purkinje cell soma size suggest the possibility of a Purkinje cell defect. However, these observations are also consistent with a hypothesis of altered afferent input to the Purkinje cells. In the visual system, for example, monocular deprivation results in reduced cell body size in the layers of the lateral geniculate nucleus receiving the interrupted input (Kupfer and Palmer, 1964; Chow and Stewart, 1972; Guillery, 1972). Similarly, a change in afferent input to the Purkinje cells of the $d t$ rat with subsequent change in Purkinje cell activity could be responsible for the reduction in the size of the target neuron. Biochemical similarities between dystonic rats and rats with 3-AP lesions of the climbing fibers also suggest the possibility that input to the Purkinje cells may be altered in the cerebellum of $d t$ rats. Both $d t$ rats and 3-AP-treated rats have large decreases in cerebellar cGMP (Guidotti et al., 1975). In addition, recent data (Oltmans et al., 1985) indicate that 3-AP lesions produce increases in GAD activity in the deep cerebellar nuclei of normal rats, a condition also observed in $d t$ rats. Thus, it is possible that there is a subtle defect in climbing fiber-Purkinje cell transmission or in the Purkinje cell response to climbing fiber input.

A reduced efficiency in normal climbing fiber-Purkinje cell interaction could be the result of an abnormal noradrenergic projection to the cerebellum of the $d t$ rat (Lorden et al., 1984). In young animals, iontophoretically applied NE has been shown to enhance Purkinje cell activity to climbing fiber input (Moises et al., 1983). A change in noradrenergic modulation of Purkinje cell activity could contribute to the reduced response of these cells to the climbing fiber stimulation

Figure 4. Sagittal sections through the brainstem showing HRP-stained cells in the inferior olive of 20-day-old normal (top) and dt (bottom) rats following injection of $0.03 \mu \mathrm{l}$ of $30 \% \mathrm{HRP}$ in saline into the cerebellum. Successful retrograde transport of the enzyme from the cerebellar injection site was obtained in both normal and dystonic rats. With injections in the same cerebellar region, the distribution of the HRP labeling could not be distinguished in normal and mutant rats. 


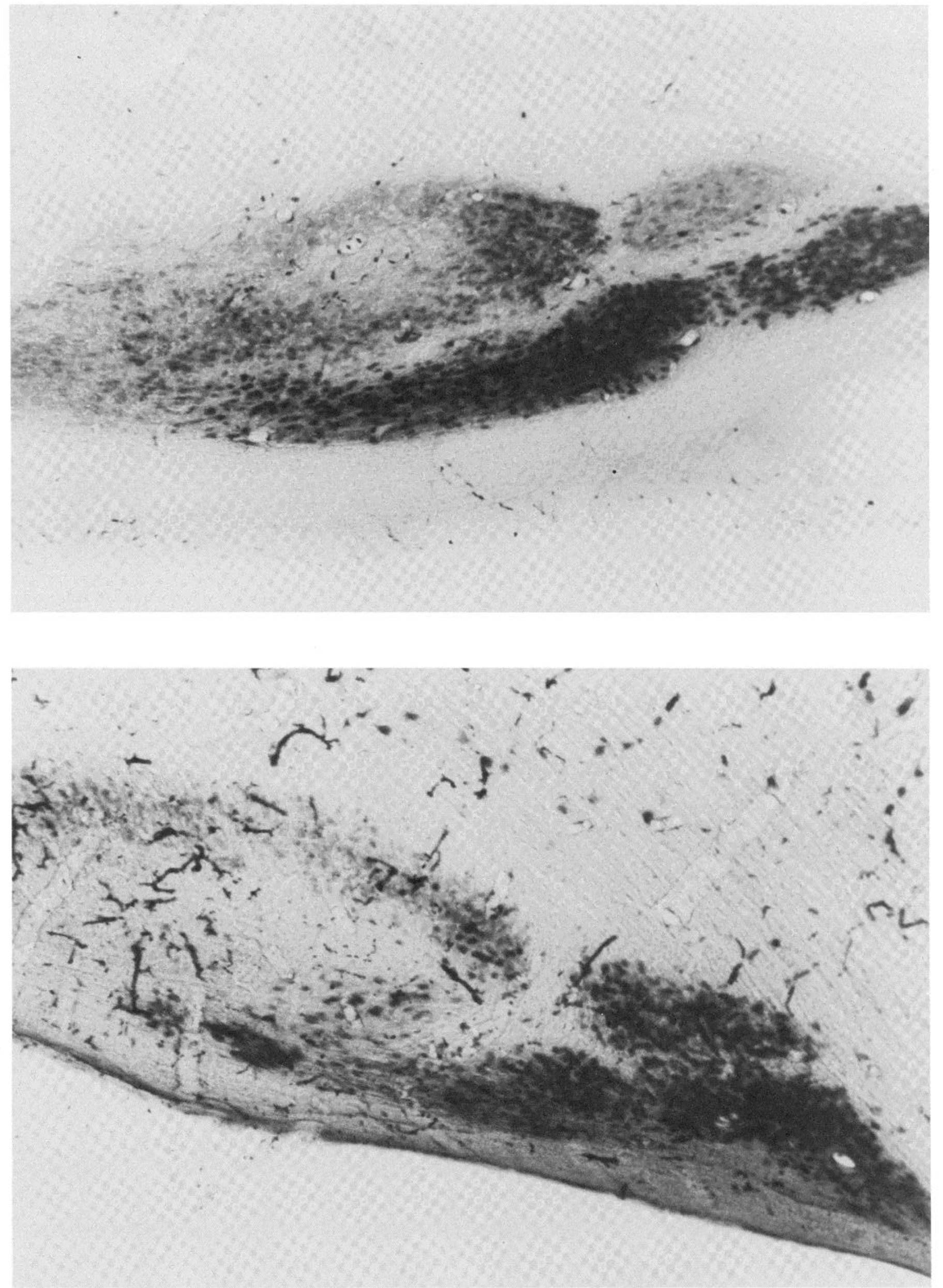


provided by harmaline treatment. It is also possible, however, that the abnormal cerebellar NE projection in the $d t$ rat is secondary to a defect in the target neurons, as has been proposed in the Purkinje cell degeneration ( $p c d$ ) mouse (Roffler-Tarlov et al., 1984).

Relation of cerebellar defects to dystonia. The sustained involuntary twisting movements and postural asymmetries symptomatic of DMD are presumed to be a consequence of biochemical disturbances in the basal ganglia (Zeman, 1970). This supposition is based primarily on the appearance of dystonic symptoms in other conditions known to affect the basal ganglia (e.g., Parkinson's disease and Huntington's chorea). Dystonias have also been reported in response to treatment with neuroleptic drugs having a site of action in the basal ganglia (Crane and Naranjo, 1971; Marsden and Harrison, 1974; Marsden, 1976; Zeman, 1976; Burke et al., 1982). It is worth noting, however, that neuroleptic drugs can also affect the cerebellum, producing decreases in cGMP levels (Biggio et al., 1978). Thus, there is no rigorous evidence available in the human disease to support a specific biochemical or anatomical etiology, since drugs that produce dystonic symptoms have cerebellar effects and data from animal models have been limited.

Because so little is known about the human disease, it is difficult to make comparisons with dystonia in rodents. Nevertheless, it is interesting to note that in the dystonia musculorum mouse, another mutant that exhibits axial dystonia (Duchen et al., 1964), biochemical abnormalities have beer found in the cerebellum (Riker et al., 1981). The dystonia in the mouse mutant is associated with significant peripheral nervous system neuropathy which distinguishes it from both the human and rat disease, and the specific pattern of neurochemical abnormalities differs from that seen in the dt rat. However, the association of dystonic postures with biochemical abnormalities of the cerebellum in two different mutants, with and without signs of peripheral nervous system degeneration, may indicate that the cerebellum may play a more pivotal role in dystonia than has previously been thought.

\section{References}

Ariano, M. A., J. A. Lewicki, H. J. Bradwein, and F. Murad (1982) Immunohistochemical localization of guanylate cyclase within neurons of the rat brain. Proc. Natl. Acad. Sci. U. S. A. 79: 1316-1320.

Biggio, G., B. B. Brodie, E. Costa, and A. Guidotti (1977a) Mechanisms by which diazepam, muscimol, and other drugs change the content of cGMP in the cerebellar cortex. Proc. Natl. Acad. Sci. U. S. A. 74: 3592-3596.

Biggio, G., E. Costa, and A. Guidotti (1977b) Pharmacologically induced changes in the $3^{\prime}, 5^{\prime}$-cyclic guanosine monophosphate content of rat cerebellar cortex: Differences between apomorphine, haloperidol, and harmaline. J. Pharmacol. Exp. Ther. 200: 207-215.

Biggio, G. M. G. Corda, M. Casu, and G. L. Gessa (1978) Effect of chronic treatment with neuroleptics on the content of $3^{\prime}, 5^{\prime}$-cyclic guanosine monophosphate in cerebellar cortex of rats. Life Sci. 23: 649-652.

Biscos, T. J., A. W. Duggan, P. M. Headley, and D. Lodge (1973) Rhythmical field potentials induced in the inferior olive complex by iontophoretically applied harmaline and other unrelated alkaloids. Br. J. Pharmacol. 49: 174-175

Breese, G. R., R. A. Mueller, and R. B. Mailman (1979) Effect of dopaminergic agonists and antagonists on in vivo cyclic nucleotide content: Relation of guanosine $3^{\prime}: 5^{\prime}$-monophosphate (CGMP) changes in cerebellum to behavior. J. Pharmacol. Exp. Ther. 209: 262-270.

Burke, R. E., S. Fahn, J. Jankovic, C. D. Marsden, A. E. Lang, S. Gollump, and J. Ilson (1982) Tardive dystonia: Late-onset and persistent dystonia caused by anti-psychotic drugs. Neurology 32: 1335-1346.

Chan-Palay, V. (1982) Neurotransmitters and receptors in the cerebellum: Immunocytochemical localization of glutamic acid decarboxylase, GABAtransaminase, and cyclic GMP and autoradiography with ${ }^{3} \mathrm{H}$-muscimol. Exp. Brain Res. (Suppl.) 6: 552-586.

Chow, K. L., and D. L. Stewart (1972) Reversal of structural and functional effects of long term visual deprivation in cats. Exp. Neurol. 34: 409-433.

Crane, G. E., and E. R. Naranjo (1971) Motor disorders induced by neuroleptics. Arch. Gen. Psychiatry 24: 179-184.

DeCamilli, P., P. E. Miller, P. Levitt, U. Walter, and P. Greengard (1984)
Anatomy of the cerebellar Purkinje cells in the rat determined by a specific immunochemical marker. Neuroscience 11: 761-817.

De Montigny, C., and Y. Lamarre (1973) Rhythmic activity induced by harmaline in the olivo-cerebello-bulbar system of the cat. Brain Res. 53: 81-95.

Duchen, L. W., S. J. Strich, and D. S. Faiconer (1964) Clinical and pathological studies of an hereditary neuropathy in mice (dystonia musculorum). Brain 87: $367-378$.

Eccles, J. C., R. Llinas, and K. Sasaki (1966a) Parallel fiber stimulation and the responses induced thereby in the Purkinje cells of the cerebellum. Exp. Brain Res. 1: 17-39.

Eccles, J. C., R. Llinas, and K. Sasaki (1966b) The excitatory synaptic action of climbing fibers on the Purkinje cells of the cerebellum. J. Physiol. (Lond.) 182: 269-296.

Eldridge, R. (1970) The torsion dystonias: Literature review and genetic and clinical studies. Neurology 20: 1-78

Guidotti, A., G. Biggio, and E. Costa (1975) 3-Acetylpyridine: A tool to inhibit the tremor and the increase of cGMP content in cerebellar cortex elicited by harmaline. Brain Res. 96: 201205.

Guillery, R. W. (1972) Binocular competition in the control of geniculate cell growth. J. Comp. Neurol. 144: 117-127.

Kupfer, C., and P. Palmer (1964) Lateral geniculale nucleus: Hislological and cytochemical changes following afferent denervation and visual deprivation. Exp. Neurol. 9: 400-409.

Lamarre, Y., and L. A. Mercier (1971) Neurophysiological studies of harmaline-induced tremor in the cat. Can. J. Physiol. Pharmacol. 49: 1049-1058.

Lamarre, Y., and E. Puil (1974) Induction of rhythmic activity by harmaline. Can. J. Physiol. Pharmacol. 52: 905-908.

Lamarre, Y., and M. Weiss (1973) Harmaline-induced rhythmic activity of alpha and gamma motoneurons in the cat. Brain Res. 63: 430-434.

Lamarre, Y., C. de Montigny, M. Dumont, and M. Weiss (1971) Harmalineinduced rhythmic activity of cerebellar and lower brain stem neurons. Brain Res. 32: 216-250.

Llinas, R., and R. A. Volkind (1973) The olivo-cerebellar system: Functional properties as revealed by harmaline-induced tremor. Exp. Brain Res. 18: $69-87$

Lorden, J. F., T. W. McKeon, H. J. Baker, N. Cox, and S. U. Walkley (1984) Characterization of the rat mutant dystonic $(d t)$ : A new animal model of dystonia musculorum deformans. J. Neurosci. 4: 1925-1932.

Lowry, O. H., N. J. Rosebrough, A. L. Farr, and R. J. Randall (1951) Protein measurement with the Folin phenol reagent. J. Biol. Chem. 193: 265-275.

Mao, C. C., A. Guidotti, and E. Costa (1974) The regulation of cyclic guanosine monophosphate in rat cerebellum: Possible involvement of putative amino acid transmitters. Brain Res. 79: 510-514.

Mao, C. C., A. Guidotti, and E. Costa (1975a) Inhibition by diazepam of the tremor and the increase of cerebellar CGMP content elicited by harmaline. Brain Res. 83: 516-519.

Mao, C. C., A. Guidotti, and S. Landis (1975b) Cyclic GMP: Reduction of cerebellar concentrations in "nervous" mutant mice. Brain Res. 90: 335339.

Marsden, C. D. (1976) Dystonia: The spectrum of the disease. In The Basal Ganglia, M. D. Yahr, ed., pp. 351-367, Raven Press, New York.

Marsden, C. D., and M. J. G. Harrison (1974) Idiopathic torsion dystonia (dystonia musculorum deformans). Brain 97: 793-810.

Moises, H. C., B. D. Waterhouse, and D. J. Woodward (1983) Locus coeruleus stimulation potentiates local inhibitory processes in rat cerebellum. Brain Res. Bull. 10: 795-804.

Nairn, A. C., and P. Greengard (1983) Cyclic GMP-dependent protein phosphorylation in mammalian brain. Fed. Proc. 42: 3107-3113.

Nieoullon, A., and N. Dusticier (1981) Increased glutamate decarboxylase activity in the red nucleus of the adult cat after cerebellar lesions. Brain Res. 224: 129-139.

Oltmans, G. A., M. Beales, J. F. Lorden, and J. Gordon (1984) Alterations in cerebellar glutamic acid decarboxylase (GAD) activity in a genetic model of torsion dystonia (rat). Exp. Neurol. 85: 216-222.

Oltmans, G. A. J. F. Lorden, and M. Beales (1985) Lesions of the inferior olive increase glutamic acid decarboxylase activity in the deep cerebellar nuclei of the rat. Brain Res., in press.

Riker, D. K., A. Messer, and R. H. Roth (1981) Increased noradrenergic metabolism in the cerebellum of the mouse mutant dystonia musculorum. J. Neurochem. 37: 649-654.

Robson, J. A. (1981) Abnormal axonal growth in the dorsal lateral geniculate nucleus of the cat. J. Comp. Neurol. 195: 453-476.

Roffler-Tarlov, S., S. C. Landis, and M. J. Zigmond (1984) Effects of Purkinje 
cell degeneration on the noradrenergic projection to mouse cerebellar cortex. Brain Res. 298: 303-311.

Schlichter, D. J., J. A. Detre, D. W. Aswad, B. Chehrazi, and P. Greengard (1980) Localization of cyclic GMP-dependent protein kinase and substrate in mammalian cerebellum. Proc. Natl. Acad. Sci. U. S. A. 77: 5537-5541. Simantov, R., S. H. Snyder, and M. L. Oster-Granite (1976) Harmaline-induced tremor in the rat: Abolition by 3-acetylpyridine destruction of cerebellar climbing fibers. Brain Res. 114: 144-151.
Sotelo, C., and M. L. Arsenio-Nurtes (1976) Development of Purkinje cells in absence of climbing fibers. Brain Res. 111: 389-395.

Sotelo, C., D. E. Hillman, A. J. Zamora, and R. Llinas (1975) Climbing fiber deafferentation: Its action on Purkinje cell dendritic spines. Brain Res. 98: 574-581.

Zeman, W. (1970) Pathology of the torsion dytonias (dystonia musculorum deformans). Neurology 20: 79-88.

Zeman, W. (1976) Dystonia: An Overview. Adv. Neurol. 14: 91-103. 